\title{
The poverty implications of climate-induced crop yield changes by 2030
}

\author{
Thomas W. Hertel ${ }^{\mathrm{a}, \mathrm{b}}$, Marshall B. Burke ${ }^{\mathrm{c}}$, David B. Lobell ${ }^{\mathrm{c}, \mathrm{d}, *}$ \\ ${ }^{a}$ Center for Global Trade Analysis, Department of Agricultural Economics, Purdue University, IN, USA \\ ${ }^{\mathrm{b}}$ Purdue Climate Change Research Center, Purdue University, IN, USA \\ ${ }^{\mathrm{c}}$ Program on Food Security and the Environment, Stanford University, Stanford, CA, USA \\ ${ }^{\mathrm{d}}$ Department of Environmental Earth System Science, Stanford University, Stanford, CA, USA
}

\section{A R T I C L E I N F O}

\section{Article history:}

Received 29 July 2009

Received in revised form 29 June 2010

Accepted 5 July 2010

\section{Keywords:}

Vulnerability

Agriculture

Food security

Hunger

\begin{abstract}
A B S T R A C T
Accumulating evidence suggests that agricultural production could be greatly affected by climate change, but there remains little quantitative understanding of how these agricultural impacts would affect economic livelihoods in poor countries. Here we consider three scenarios of agricultural impacts of climate change by 2030 (impacts resulting in low, medium, or high productivity) and evaluate the resulting changes in global commodity prices, national economic welfare, and the incidence of poverty in a set of 15 developing countries. Although the small price changes under the medium scenario are consistent with previous findings, we find the potential for much larger food price changes than reported in recent studies which have largely focused on the most likely outcomes. In our low-productivity scenario, prices for major staples rise $10-60 \%$ by 2030 . The poverty impacts of these price changes depend as much on where impoverished households earn their income as on the agricultural impacts themselves, with poverty rates in some non-agricultural household groups rising by $20-50 \%$ in parts of Africa and Asia under these price changes, and falling by significant amounts for agriculture-specialized households elsewhere in Asia and Latin America. The potential for such large distributional effects within and across countries emphasizes the importance of looking beyond central case climate shocks and beyond a simple focus on yields - or highly aggregated poverty impacts.
\end{abstract}

( 2010 Elsevier Ltd. All rights reserved.

\section{Introduction}

The recent IPCC report confirmed that global climate change is real, that it is occurring rapidly, and that roughly $1{ }^{\circ} \mathrm{C}$ of warming, relative to the late 20th century, is expected globally by 2030 regardless of what happens to emissions of greenhouse gases (Solomon et al., 2007). Accumulating evidence suggests that even this seemingly small amount of warming could have profound implications for human enterprise, and a thorough understanding of these potential impacts is central to planning appropriate responses (Parry et al., 2007).

Agriculture is one of the human activities most dependent on climate, and as a result it is one of the sectors where climate change impacts are expected to hit hardest. Despite a growing body of research on the subject, however, there remains significant uncertainty as to the nature and timing of the climate impacts on agriculture, as well as the implications of these agricultural impacts for human livelihoods around the world (Easterling et al., 2007; Schmidhuber and Tubiello, 2007). Most existing research has

\footnotetext{
* Corresponding author at: 473 Via Ortega, Stanford, CA 94305, USA. Tel.: +1 6507216207

E-mail address: dlobell@stanford.edu (D.B. Lobell).
}

focused on the likely direct climate impacts on crop yields and agricultural output (Jones and Thornton, 2003; Funk et al., 2008; Lobell et al., 2008), but direct crop impacts in a given area provide only partial understanding of the consequences for human livelihoods. This is both because countries - and hence production systems - are inter-connected through trade, but also because different households are affected by these price changes in different ways. For instance, households selling their surplus production in local markets could benefit if climate change causes food prices to rise, even as their non-farming neighbors are hurt by higher prices.

Unfortunately, the few studies that do attempt to quantify livelihood impacts typically rely on coarse country- or regionallevel aggregations for their economic analysis, and so are unable to either resolve these potential distributional effects or shed light on the various mechanisms that might produce them (Rosenzweig and Parry, 1994; Fischer et al., 2005). Furthermore, these studies' estimates of agricultural impacts do not always span the plausible range of impacts suggested by recent research, and the mechanics of their modeling framework are not always transparent, providing little insight into the uncertainty associated with estimated impacts. As a result, existing work gives little guidance to decision-makers who need to know which groups in particular will gain or lose, the reasons why this will happen, and the degree of certainty associated with these estimates. 

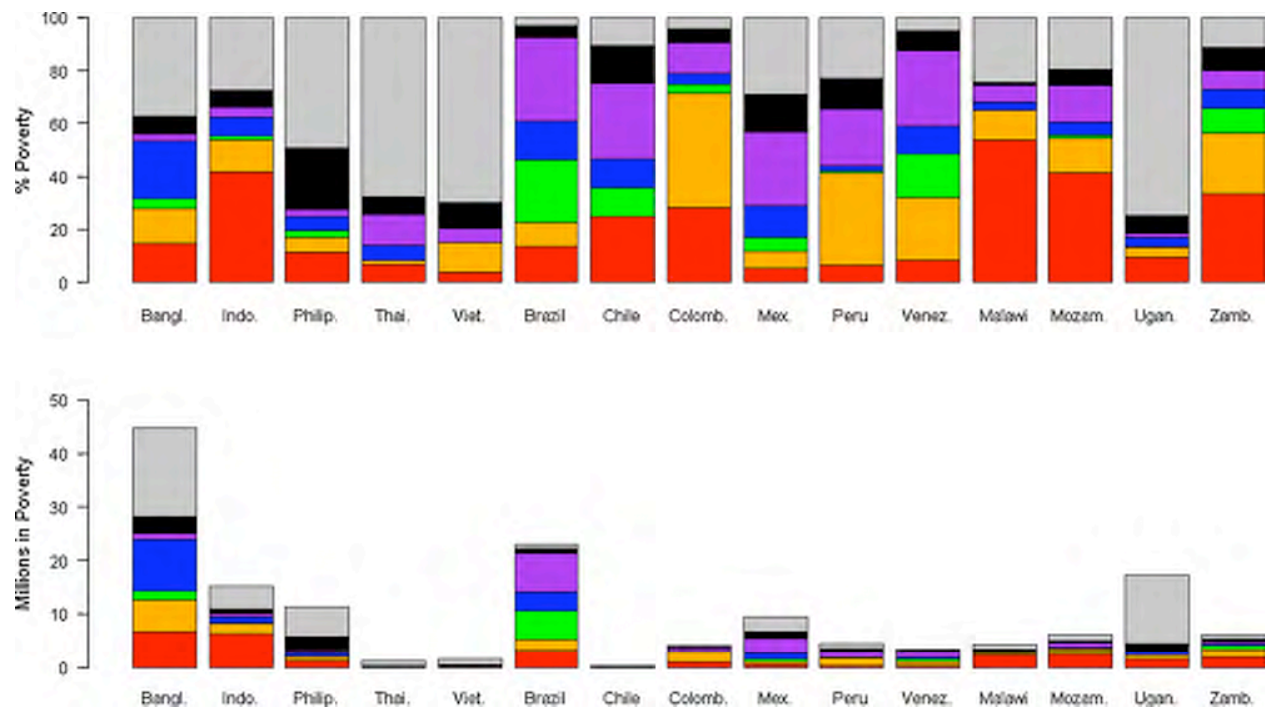

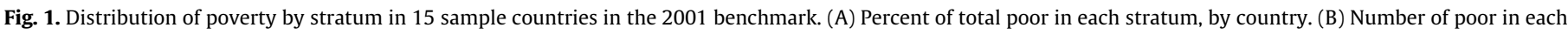

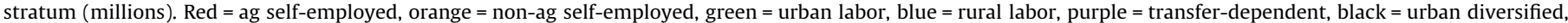
gray = rural diversified. (For interpretation of the references to color in this figure legend, the reader is referred to the web version of the article.)

Here we use disaggregated data on household economic activity within individual countries, and embed these data within a well-documented global trade model (the Global Trade Analysis Project (GTAP) general equilibrium model) to explore how changes in agricultural productivity as a result of climate change will affect poverty in poor countries (see Section 2). In particular, we explore the various pathways by which climate change might affect agricultural incomes and food prices, and the resultant effects of these changes on the welfare of low-income households engaged in the full range of economic activities in developing countries.

\section{Materials and methods}

\subsection{GTAP model}

To estimate the impacts of agricultural productivity shocks on poverty, we use the Global Trade Analysis Project (GTAP) general equilibrium global trade model and its accompanying database and recently developed poverty modules (Hertel, 1997; Dimaranan, 2006; Hertel et al., 2007). GTAP is a widely used, comparative static, general equilibrium model which exhaustively tracks bilateral trade flows between all countries in the world, and explicitly models the consumption and production for all commodities of each national economy. Producers are assumed to maximize profits, while consumers maximize utility. Factor market clearing requires that supply equal demand for agricultural and non-agricultural skilled and unskilled labor and capital, natural resources and agricultural land, and adjustments in each of these markets in response to the climate change shocks determines the resulting wage and rental rate impacts. The model has recently been validated with respect to its performance in predicting the price impacts of exogenous supply side shocks, such as those that might result from global climate change (Valenzuela et al., 2007) (see Appendix A for more detail).

Although GTAP could be used to look at impacts of climateinduced productivity shocks in any sector of the economy, this paper focuses on productivity shocks in agriculture given its particular sensitivity to climate change as well as the sector's important role in poverty determination. The model allows us to trace the aggregate effects of these shocks on the macro economy, and to understand how the shocks are transmitted to households living near the poverty line. To explore these poverty impacts, we stratify households within countries by their primary source of income. Following Hertel et al. (2004), we identify 5 household groupings that earn $>95 \%$ of their income from one source: agricultural self-employment, non-agricultural self-employment, rural wage labor, urban wage labor, or transfer payments (such as remittances or government aid). The remaining households not categorized in these 5 strata are grouped as rural diversified or urban diversified. The concentration of poverty in each of these strata can differ widely from country to country, for instance with Malawi having nearly half of its poor in agricultural self-employed households, and Colombia near half its poor in non-agricultural self-employed households (see Fig. 1). These poverty shares, coupled with data on earnings and consumption shares, as well as poverty-income elasticities, permit us to predict changes in poverty headcount by stratum, given the price and earnings changes produced by the GTAP model.

\subsection{Productivity shocks}

Productivity shocks in agriculture due to climate change between 2000 and 2030 were prescribed based on a synthesis of values from the literature for the GTAP regions and six commodities (rice, wheat, coarse grains, oilseeds, cotton, and other crops) (see Appendix B for specified yield shocks). A "most likely" or "central case" estimate was made for each region/ commodity pair, along with an estimate of "low-productivity" and "high-productivity" outcomes. The low-productivity scenario depicts a world with rapid temperature change, high sensitivity of crops to warming, and a $\mathrm{CO}_{2}$ fertilization effect at the lower end of published estimates. The high-productivity scenario represents a world with relatively slow warming, low sensitivity of crops to climate change, and high $\mathrm{CO}_{2}$ fertilization. These estimates are intended to bracket a range of plausible outcomes, and can be thought of as the 5th and 95th percentile values in a distribution of potential yield impacts. Specifically, for each crop-region, we selected values for optimistic and pessimistic climate projections from Christensen et al. (2007), optimistic and pessimistic crop sensitivities from studies within each region, and optimistic and pessimistic $\mathrm{CO}_{2}$ fertilization effects from Ainsworth et al. (2008). For an example at the global scale, see Tebaldi and Lobell (2008).

The magnitude and geographic patterns of yield impacts in the central case are consistent with previous impact syntheses (Cline, 

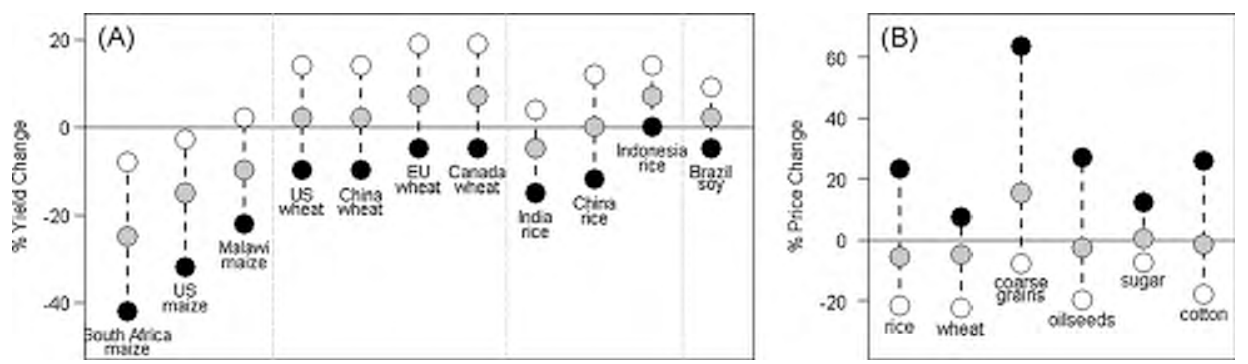

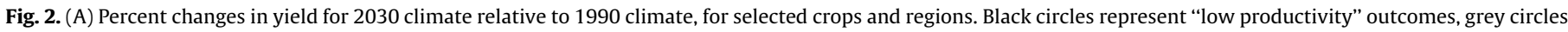
the "central case" outcomes, and white circles the "high-productivity" outcomes. (B) Average world price change for six commodity groups under same scenarios.

2007; Easterling et al., 2007), but we rely on our own estimates because (i) they include more recent studies not considered in previous syntheses and (ii) they allow for consistency across the three scenarios, whereas most other studies provide only a central or "consensus" estimate but do not estimate the tails of the distributions.

When no information was found for a specific region or commodity, we used the value from a neighboring region or similar crop. For example, few studies were found for cotton, and in these cases we used similar values as for rice. Sugarcane was assumed to have no response throughout the analysis, given that the few available studies of sugarcane show small net impacts of climate and $\mathrm{CO}_{2}$ changes.

Estimates were made without consideration of adaptations that may reduce negative or enhance positive outcomes, such as the development of new crop varieties or the significant expansion of irrigation infrastructure in a region. As such, we treat these as pure "productivity shocks" in the GTAP model. However, adverse productivity shocks can engender significant price rises, which is a finding of the paper, and these can provide an incentive to invest additional resources in the sector. This form of adaptation is endogenous to the model and is modeled through production functions which vary by crop and region and which allow substitution of labor, capital and purchased inputs for land in response to such climate-induced scarcity.

Finally, rather than projecting the entire world economy forward to the year 2030, we adopt the much simpler approach of imposing the climate change shocks on our base year economy (2001). This is not because intervening changes in the global economy will be unimportant. On the contrary, as will be discussed in our concluding section, the global composition of poverty in 2030 will be critical to these outcomes. However, little is known about how global poverty will evolve over the coming decades. Rather than confusing the reader by adding another source of uncertainty to the analysis, we prefer to simply overlay the climate shocks on a global economy/ poverty distribution that has been recently observed.

\section{Results and discussion}

\subsection{Productivity shocks and price changes}

Climate-induced yield shocks for this 30 -year period for some key regions and crops are shown in Fig. 2a. Maize and other coarse grains exhibit the largest potential negative outcome. This reflects recent studies' finding of a low responsiveness of $\mathrm{C}_{4}$ crops to increased $\mathrm{CO}_{2}$ concentrations (Long et al., 2006; Ainsworth et al., 2008) and high sensitivity to extreme heat in both temperate and tropical maize (Schlenker and Roberts, 2008; Schlenker and Roberts, 2009), and is consistent with estimates of maize yield losses due to warming since 1980 (Lobell and Field, 2007). Estimates of the impact of climate change on wheat and rice yields typically span zero across low- and high-productivity cases, and include the possibility of large yield gains in currently cold-limited wheat systems in regions such as the EU and Canada (see Appendix B).

The estimated changes in global commodity prices from GTAP as a result of these shocks are quite small for the central case for most commodities, although coarse grains prices are projected to increase by $15 \%$ (Fig. 2b). The average world price rise for all cereals is just 3.6\% which is consistent with previous global projections of near-zero cereal price changes for approximately $1^{\circ} \mathrm{C}$ of warming (Easterling et al., 2007). However, the low-productivity and highproductivity scenarios indicate the potential for large price impacts, with an average rise of $32 \%$ for cereals (and $63 \%$ for coarse grains) in the former case, and drop of $16 \%$ in the latter. ${ }^{1}$ As most previous studies focus only on the expected outcome, the magnitude of these lower-probability but feasible outcomes is larger than anything previously reported.

\subsection{Macro-economic effects of climate change}

Although agriculture represents only $2.4 \%$ of global GDP, its share is much larger in poor countries, with the agricultural sector representing $>40 \%$ of the value-added for all goods and services in many poor countries. Given this important role of the farm sector in the broader economic performance of poor countries, the potential macro-economic effects of climate change on agricultural production are of immediate interest, and set the broad context for discussion of poverty impacts.

The regional welfare impacts of agricultural productivity shocks, expressed as a percentage of crop sector value-added, can be decomposed into three components, as illustrated in Fig. 3 which reports two of these three, along with the total. (The third may be obtained by subtraction.) The first (dark grey) component corresponds to the direct economic valuation of the estimated productivity shocks. For the low-productivity scenario (Fig. 3a), this contribution is negative in all regions, reflecting the general worsening of crop production conditions worldwide, but with the severity varying widely across regions. Model projections suggest the highest percentage losses owing to the direct impact of climate change on crops in the Sub-Saharan Africa region, with relatively large losses also for the US and China.

Given the relatively inelastic demand for food throughout much of the world, such declines in production result in significant price increases for agricultural commodities as shown in Fig. 2b. These price rises affect the second component of economic welfare, the terms of trade (ToT) for each country, with net exporting countries gaining from higher priced products while net importers of agricultural productions experience a deterioration in their ToT.

\footnotetext{
${ }^{1}$ Agricultural price changes are a function of the total price responsiveness of the economy, including the scope for intensification of production, expansion of production into new area, as well as the price elasticity of demand (Hertel, 2011). The larger these price elasticities of supply and demand, the smaller the ensuing price rise following an adverse yield shock. In our model, these elasticities are based on econometric studies of agricultural supply and demand (Keeney and Hertel, 2005)
} 

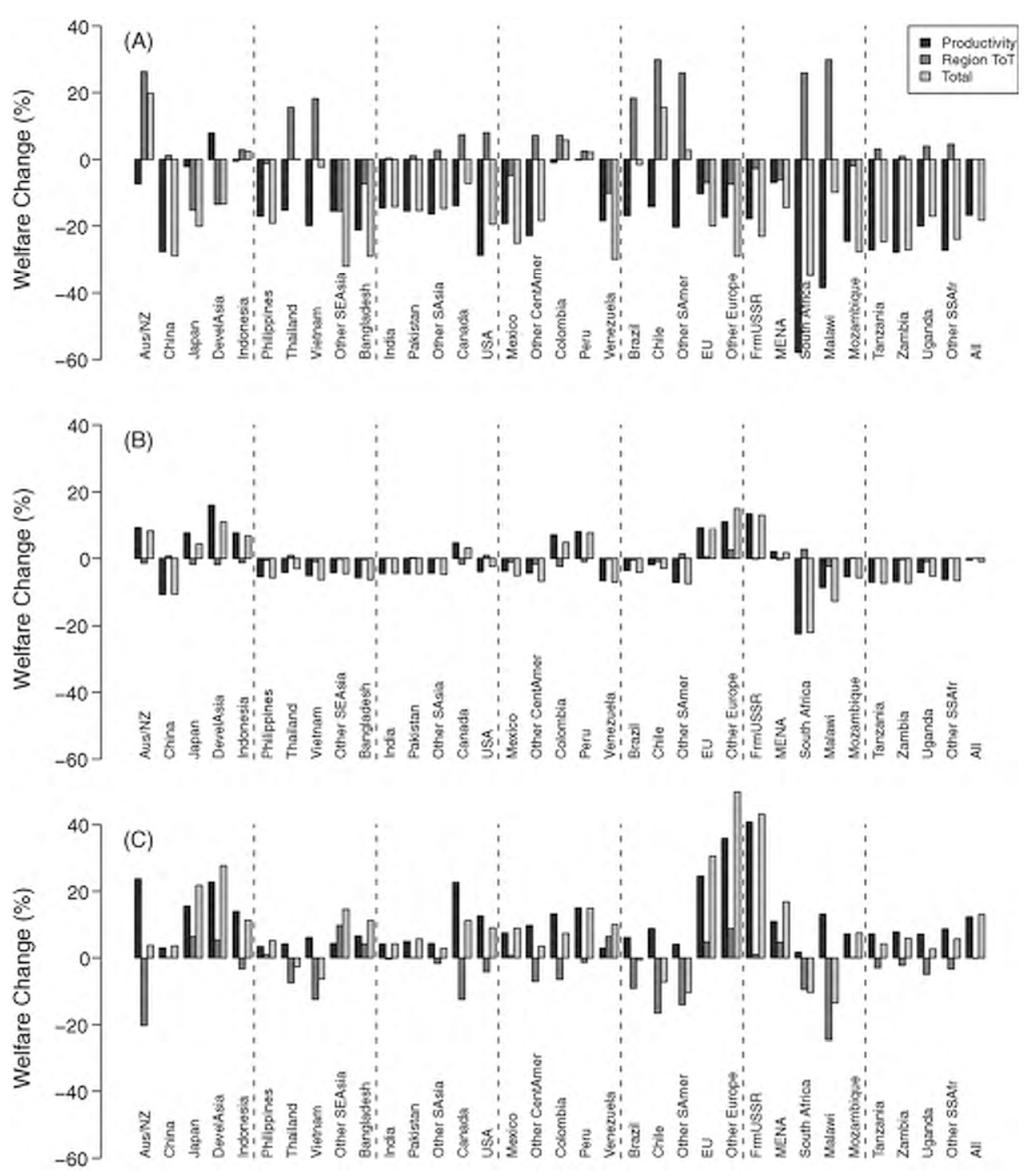

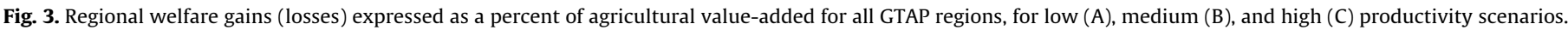

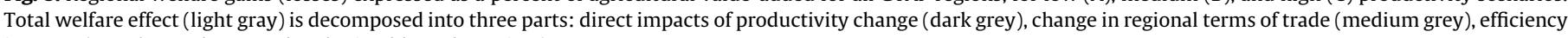
impacts (not shown, but may be obtained by subtraction.).

The value of the ToT effect, expressed as a percentage of initial crops sector value-added, can be very important for nations that trade extensively in agricultural products. In Australia/New Zealand and Brazil, for instance, aggregate gains from ToT shifts outweigh the losses due to the direct effect of climate change. Some of the African regions also show sizable ToT gains, although these are not large enough to offset the direct losses in the lowproductivity scenario.

The third and final component of regional welfare change is the change in economic efficiency, which captures the interaction between the impacts of climate change and existing food, agricultural and non-agricultural policies. (This is omitted from Fig. 3 to avoid excessive clutter.) To the extent that climate change causes global trade to shrink, and to the extent that global trade volumes are already lower than economically optimal due to the presence of tariffs, this will lead to an efficiency loss. As a result of declining trade volumes, we observe a negative welfare contribution from economic efficiency equal to $1.5 \%$ of global crops sector GDP under the low-productivity scenario. When added to the direct impact of climate change on the cropping economy, global welfare declines by $\$ 123$ billion, or about $18 \%$ of global crops sector GDP under this pessimistic scenario.
In the central case scenario shown in Fig. 3b, the direct effects of productivity change are mixed, with productivity rising for some commodities/regions and falling for others. As a consequence, the global valuation of the direct productivity impacts is close to zero ( $-0.5 \%$ of crops GDP). The efficiency impact is also much smaller (just $-0.4 \%$ of crops GDP), so the global loss is much smaller than in the low-productivity case. In the high-productivity case (Fig. 3c), the direct effects of the productivity change are positive for all model regions, and world trade rises, thereby boosting the efficiency effect. The global gain in this case is $+13 \%$ of crops GDP.

\subsection{Poverty effects of climate change}

Rising world prices for staple commodities may result in a substantial reduction in real income - and an increase in poverty for households spending a large share of their income on staple grains. However, the well-being of poor households depends not only on changes in the cost of living, but also on changes in earnings. Previous research on the effect of international trade reforms on poverty suggests that the earnings effects of commodity market changes can dominate the ensuing poverty impacts (Hertel and Winters, 2006). Indeed, the impact of adverse 
productivity shocks on farm incomes hinge critically on the extent to which rural producers are integrated into markets; if they are price-takers for outputs, then the income effects of such a productivity shock depend critically on the farm-level price elasticity of demand facing producers (Hertel and Rosch, 2010). When farm-level demand is inelastic, then a supply reduction will boost incomes, and vice versa. Therefore it is essential to examine the impact of climate change shocks on factor incomes as well as the cost of living for poor households.

To identify the differential earnings impacts on different groups of poor households, we use household survey data for 15 developing countries in Africa, Asia and Latin America (Hertel et al., 2004). Households in each country are stratified into seven groups based on their primary source of earnings (i.e. where they earn $95 \%$ of their income): agricultural self-employed (farm income), non-agricultural (non-agricultural self-employment earnings), urban labor (urban household, wage labor income), rural labor (rural household, wage labor income), transfer payment dependent, urban diverse, and rural diverse. The last two groupings absorb the households with non-specialized income sources, residing in the urban and rural areas, respectively.

Fig. 4 plots the median stratum-specific poverty impacts of the three climate scenarios against the average world price change for staple commodities under each scenario, decomposing the separate effects of cost of living changes and earnings changes. For present purposes, we adopt the World Bank definition of poverty headcount as the portion of a nation's population living on less than $\$ 1 /$ day (Chien and Ravallion, 2001). While world prices for staple grains rise by an average of more than $30 \%$ in the lowproductivity scenario, the average impact on the real cost of living at the poverty line is more modest - just $6.3 \%$ in our sample. There are several reasons for this: the rise in prices of consumers' food products is dampened by the role of other factors in the consumption goods (e.g., transport, marketing) the prices of which are little affected; consumers adjust their consumption bundle to account for the new pattern of prices; and finally, staple grains are only one part of the total consumption bundle. Since all households in each region face the same prices and have the same preferences, the change in the estimated real cost of living at the poverty line is the same across strata for any given country.

The cost of living-driven poverty change (Fig. 4a) is the product of the percentage change in the real cost of living at the poverty line and the stratum-specific elasticity of poverty with respect to real income, wherein the latter is derived from the survey data. Differences in the median impact of cost of living changes on poverty for different types of households are a result of differences in poverty elasticities across strata within each country. Poverty increases from changes in the cost of living are largest for the urban wage labor household stratum, where the stratum density around the poverty line is relatively high, while the transfer and agriculture-dependent households show the smallest change. In the case of the central case productivity scenario, the median change in poverty is negligible, while in the high-productivity scenario, the lower world prices (Fig. 4a) result in a poverty reduction for all strata, based solely on the cost of living change.

Effects on earnings (Fig. 4b) exhibit much greater dispersion in poverty impacts in the low and high-productivity scenarios. In the low-productivity climate scenario, rising world commodity prices translate into increased returns to factors employed in agriculture, and, to the extent that purchased input prices are unaffected, the impact of the agriculture-specific factors tend to be "magnified" as they absorb the full impact of the price change. Furthermore, unlike the cost of living effect, wherein all households are diversified (i.e. they consume both food and nonfood goods and services), many households are specialized on the earnings side (e.g., they may earn virtually all of their income from agriculture). Consequently, we see bigger swings in earnings for the specialized households than we saw in their cost of living, with a sharp increase in earnings and drop in the poverty rate for the agricultural self-employed households. On the other hand, poverty rises for the non-agricultural specialized households, the returns to which fall due to the decline in the relative price of non-agriculture commodities, compared to agriculture goods. The wage labor and diversified households show less of an earnings impact, as they are not subject to the magnification effect that applies to sectorspecific earnings.

Fig. $4 \mathrm{~b}$ also reports the earnings-driven poverty impacts from the medium- and high-productivity climate scenarios. As with the cost of living effects, the medium productivity scenario shows little change in the poverty rates, on average. However, in the highproductivity case, earnings-driven poverty changes are quite sharp for the agricultural specialized households, as well as for the diversified households, many of which obtain a portion of their income from agriculture enterprises. This is true even in the case of urban diversified households, which may have recently moved to the city, or which may include members still active in agriculture.

Combining the cost of living and earnings impacts on poverty, we obtain the total poverty impact (Fig. 4c) which indicates that the median poverty impacts on agricultural self-employed households are positively correlated with the productivity shock - with lower global productivity generating higher agricultural prices and reduced poverty amongst these households, as well as the diversified households. The opposite is true of the non-agricultural self-employed households as well as the transfer-dependent households. Median poverty rises in all cases for the urban wage labor household group. The net change in national poverty depends on the contribution of each stratum to overall poverty, which is indicated by the area of each circle in Fig. 4. For example,
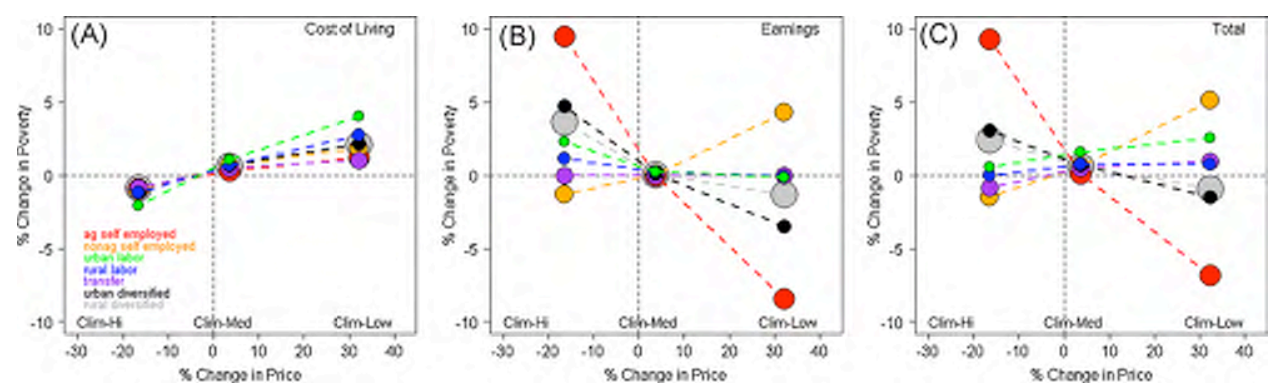

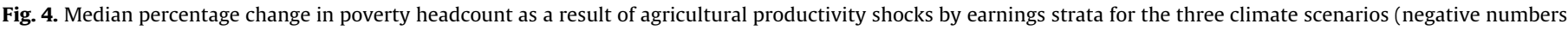

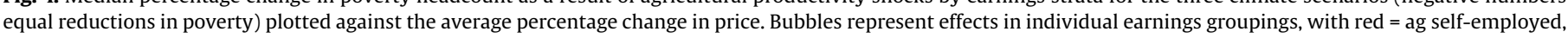

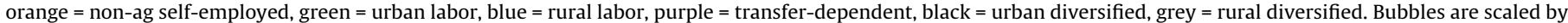

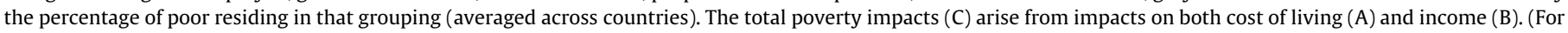
interpretation of the references to color in this figure legend, the reader is referred to the web version of the article.) 

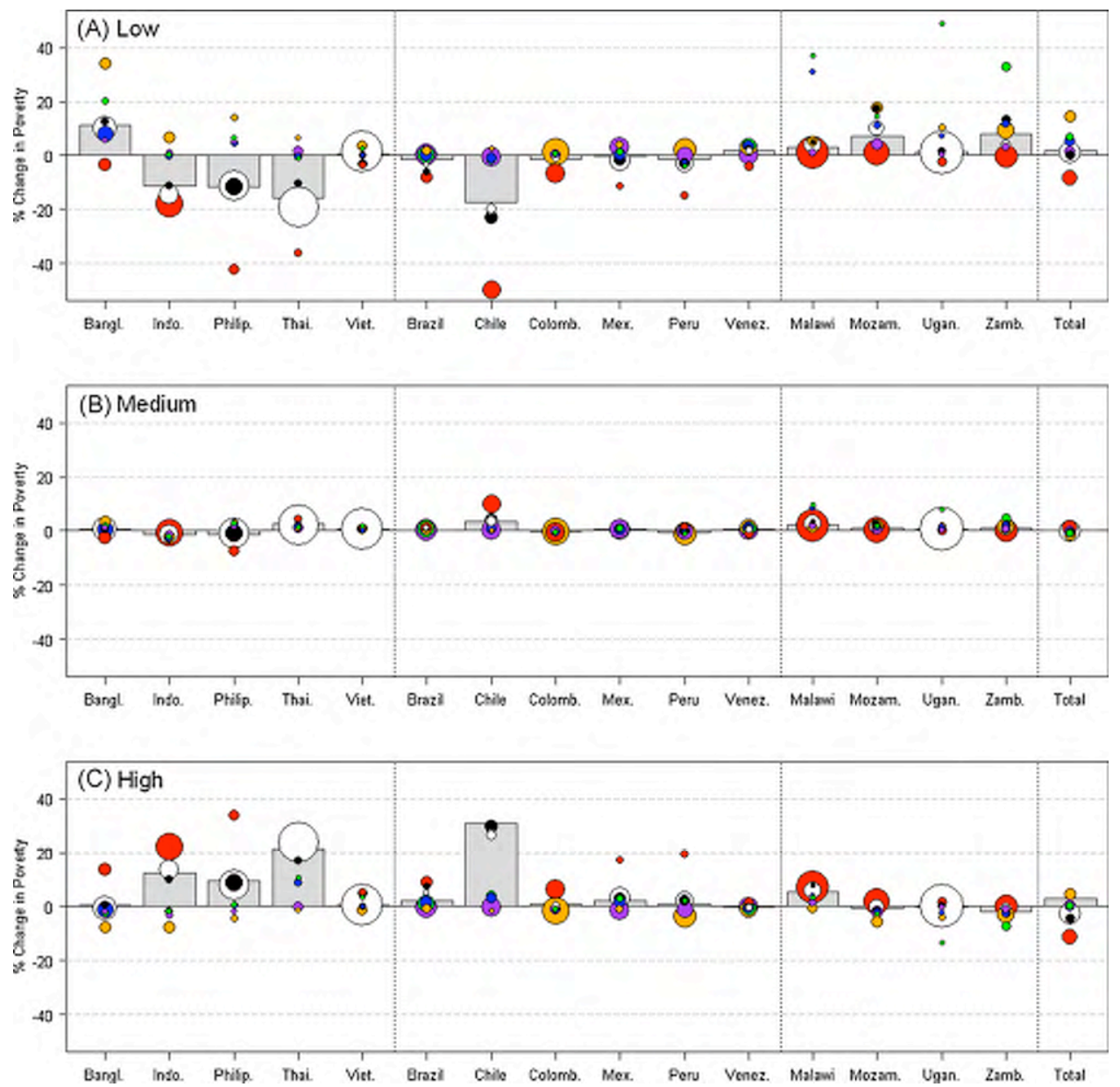

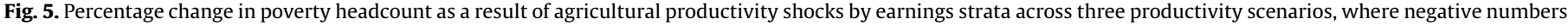

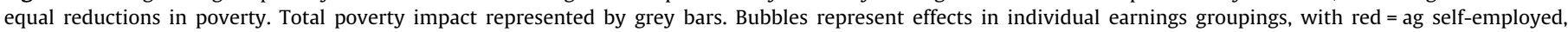

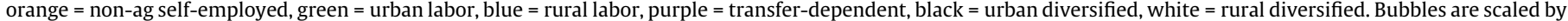

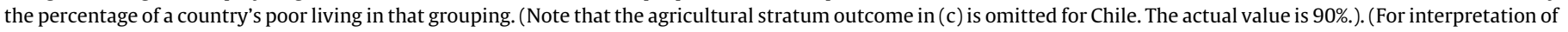
the references to color in this figure legend, the reader is referred to the web version of the article.)

the rural diversified and agriculture-dependent strata tend to contain a large share of the poor in our country sample, so these changes are particularly important. On the other hand, the urban wage labor households tend to contribute a much smaller share to national poverty.

The overall, and by stratum, poverty changes across all countries are reported in Fig. 5. For the low-productivity scenario, these illustrate that nearly all countries have some strata where poverty is increased and others where poverty is decreased. The exception is most African countries, where yield impacts of climate change are severe and no stratum experiences significant poverty reductions. At the other end of the spectrum, countries such as Indonesia and Chile incur relatively small yield losses compared to other countries, and therefore higher world prices result in large poverty declines in the agricultural sector, leading in turn to overall poverty reductions. Although eight out of 15 countries in Fig. 5 exhibit poverty decreases for the low-productivity scenario, cumulative poverty in the sample increases by $2.7 \mathrm{M}$ people for these 15 countries, or $1.8 \%$, because countries with larger populations and more poor in our sample tend to be more negatively affected (e.g., Bangladesh).

On the other hand, in the high-productivity scenario, poverty rises in all the countries where it fell under the low-productivity scenario, and falls in four countries where it had risen under the low-productivity case. Global poverty rises slightly in this case as well. The lack of symmetry in the overall results reflects the enormous variation in poverty impacts across strata and countries, and the lack of symmetry in the climate shocks between the high and low-productivity scenarios. In the central case, poverty changes in all countries are muted, as one would expect from the modest productivity and price changes.

\section{Conclusions}

This study presents four important lessons for scientists and policy makers concerned with poverty responses to climate change in the near term (by 2030). First, although previous global assessments have gravitated toward estimates of the most likely scenario, we find that global cereal price changes could be considerable at the tails of the distribution, with a $32 \%$ price increase for a low-productivity (high negative impact) scenario and a $16 \%$ price decline under a more optimistic yield scenario. Thus it is important to consider the full range of possibilities in designing policy responses, particularly given that these estimated potential price changes are well outside the range of changes predicted in the recent IPCC report for a similar level of warming.

Second, although most studies focus on aggregate yield or production impacts, these measures provide a relatively poor predictor of regional welfare impacts, because international trade is an important mediator between countries which are differentially affected by climate change shocks to agricultural productivity. Despite experiencing significant negative yield shocks, some 
countries (e.g., Brazil) stand to gain from higher commodity prices. Indeed, the rise in price more than offsets the adverse impact of lower agricultural productivity in some cases.

Third, yield changes are even poorer predictors of likely changes in national poverty, because the price-induced earnings changes can be a more important driver of household poverty than the commodity price changes themselves. Furthermore, while climate change has a fairly consistent impact on the real cost of living at the poverty line, the impact on household earnings is quite varied. In regions where the bulk of the poor are self-employed in agriculture and adverse productivity impacts are relatively modest, higher global agricultural prices can boost factor returns in the sector, thereby reducing overall poverty. On the other hand, when poverty is dominated by wage earners and urban poverty, the opposite applies. In short, understanding climate change impacts on poverty requires detailed empirical knowledge both of the pattern of agricultural productivity shocks as well as the patterns of trade, production, consumption and poverty in the countries in question.

Finally, if outcomes in either tail of the agricultural yield distributions are realized by 2030, the magnitude of the resulting poverty changes among some segments of the population in developing countries is potentially large. We focus particularly on the high price/low-productivity scenario, in which case poverty increases by as much as one-third in the urban labor (Malawi, Uganda and Zambia) and non-agricultural self-employed (Bangladesh) strata. In contrast, poverty falls sharply in the agricultural self-employed stratum in Chile, Indonesia, Philippines and Thailand as rising world prices more than compensate producers in these regions for their relatively modest losses in productivity. Given these potentially significant poverty impacts, reducing uncertainty in the estimated agricultural impacts of climate change is a high priority for future research as well as policy analysis aimed at targeting assistance to those most likely to be affected by climate change.

\section{Acknowledgements}

This work was supported by Funding from the Rockefeller Foundation as well as the World Bank's Trust Fund for Environmentally Sustainable Development.

\section{Appendix A. Structure of GTAP model}

The Global Trade Analysis Project (GTAP) model is a multicommodity, multi-regional computable general equilibrium model documented in a book, published by Cambridge University Press (Hertel, 1997) with detailed discussion on theory and derivation of the behavioral equations involved in the model. The standard GTAP model employs the simple, but robust, assumptions of constant returns to scale and perfect competition in all the markets with Walrasian adjustment to ensure a general equilibrium. As represented in the figure below (Brockmeier, 2001), the regional household (e.g., the EU) collects all the income in its region and spends it over three expenditure types - private household (consumer), government, and savings, as governed by a Cobb-Douglas utility function. A representative firm maximizes profits subject to a nested Constant Elasticity of Substitution (CES) production function which combines primary factors and intermediates inputs to produce a final good. Firms pay wages/rental rates to the regional household in return for

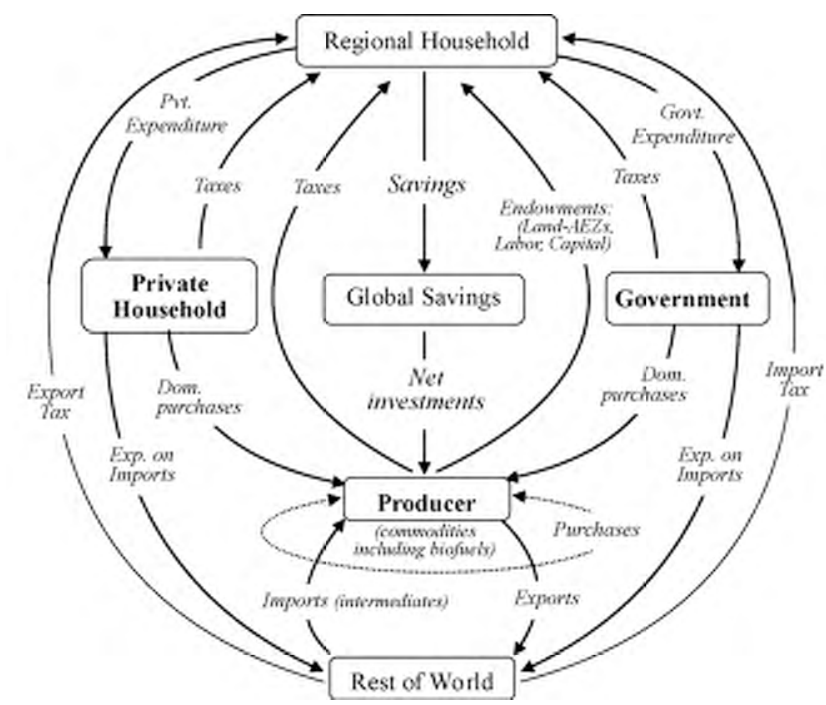

Fig. A1. Schematic of GTAP model.

the employment of land, labor, capital, and natural resources. Firms sell their output to other firms (intermediate inputs), to private households, government, and investment. Since this is a global model, firms also export the tradable commodities and import the intermediate inputs from other regions. These goods are assumed to be differentiated by region, following the Armington assumption, and so the model can track bilateral trade flows. See Fig. A1 for a schematic of the GTAP approach.

Agricultural land is imperfectly mobile across uses. Labor and capital markets are segmented, allowing for differential returns between the agriculture and non-agriculture sectors and immobile across countries. Government spending is modeled by using a CobbDouglas sub-utility function, which maintains constant expenditure shares across all budget items. The private household consumption is modeled with a non-homothetic Constant Difference of Elasticity (CDE) implicit expenditure function, which allows for differences in price and income elasticities across commodities. Taxes (and subsidies) go as net tax revenues (subsidy expenditures) to the regional household from private household, government, and the firms. The rest of the world gets revenues by exporting to private households, firms and government. In the GTAP model, this rest of world composite is actually made up of many other regions - with the same utility and production functions as for the regional household at the top of this figure.

In this paper, we employ the standard GTAP model closure which imposes equilibrium in all the markets, where firms earn zero-profits, the regional household is on its budget constraint, and global investment equals global savings. The global trade balance condition determines the world price of a given commodity.

\section{Appendix B. Prescribed productivity shocks (\%) in each scenario by commodity group}

See Table B1. 
Table B1

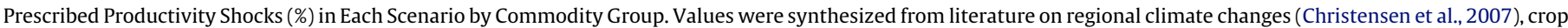

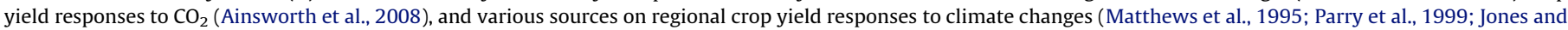
Thornton, 2003; Lin et al., 2005; Alcamo et al., 2007; Cline, 2007; Xiong et al., 2007; Lobell et al., 2008; Tebaldi and Lobell, 2008; Schlenker and Roberts, 2009).

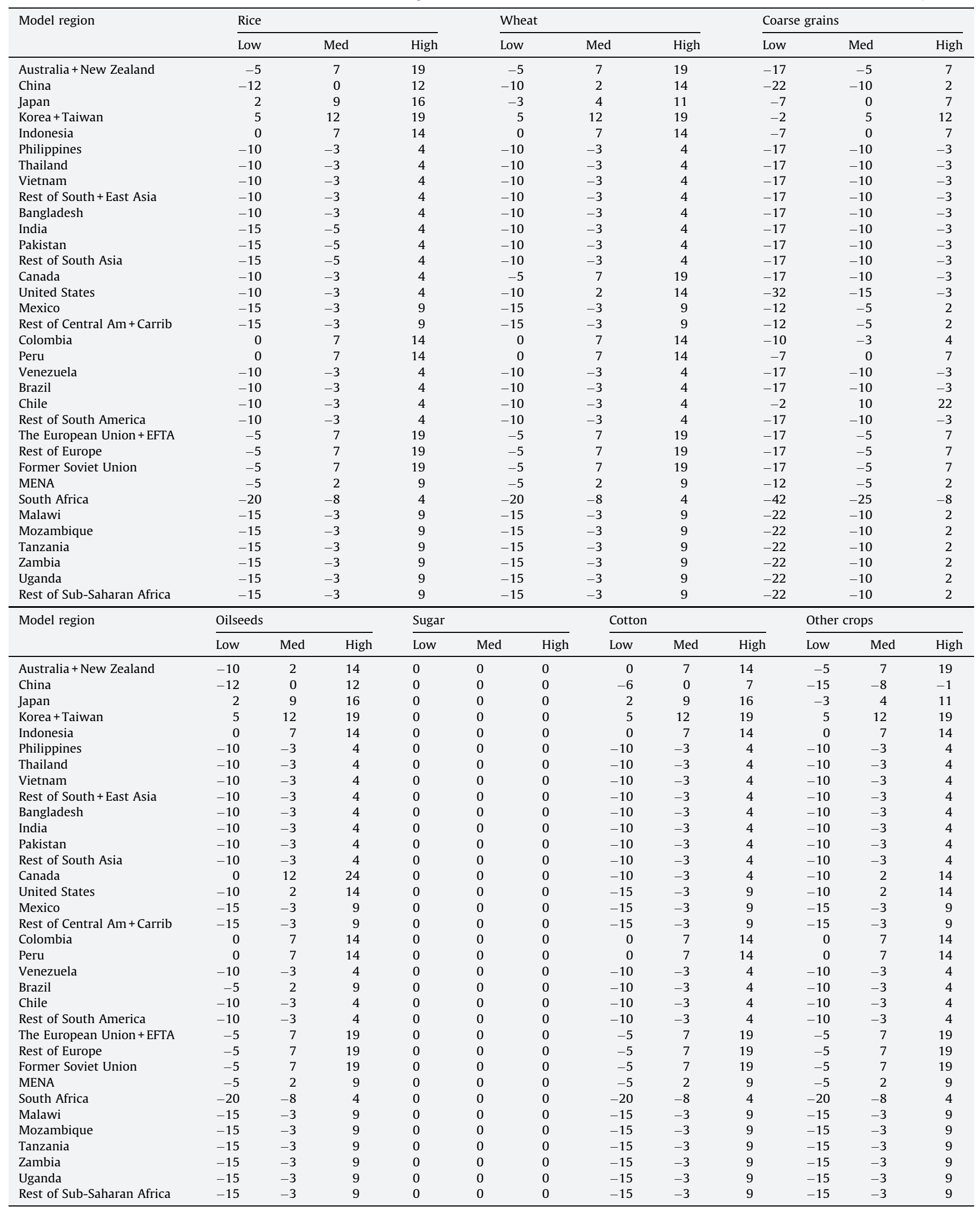




\section{References}

Ainsworth, E.A., Leakey, A.D.B., Ort, D.R., Long, S.P., 2008. FACE-ing the facts: inconsistencies and interdependence among field, chamber and modeling studies of elevated $\mathrm{CO}_{2}$ impacts on crop yield and food supply. New Phytologist 179 (1), 5-9.

Alcamo, J., Dronin, N., Endejan, M., Golubev, G., Kirilenko, A., 2007. A new assessment of climate change impacts on food production shortfalls and water availability in Russia. Global Environmental Change 17 (3-4), 429-444.

Brockmeier, M., 2001. A Graphical Exposition of the GTAP Model. GTAP Technical Paper, 8.

Chien, S., Ravallion, M., 2001. How did the world's poorest fare in the 1990s? The Review of Income and Wealth 47 (3), 283-300.

Christensen, J.H., et al., 2007. Regional climate projections. In: Solomon, S., et al (Eds.), Climate Change 2007: The Physical Science Basis. Contribution of Working Group I to the Fourth Assessment Report of the Intergovernmental Panel on Climate Change. Cambridge University Press, Cambridge, United Kingdom and New York, NY, USA.

Cline, W.R., 2007. Global Warming and Agriculture: Impact Estimates by Country. Center for Global Development, Washington, D.C., 250 pp.

Dimaranan, B.V. (Ed.), 2006. Global Trade Assistance and Protection: The GTAP Data base Centre for Global Trade Analysis. Purdue University, West Lafayette, Indiana.

Easterling, W., et al., 2007. Chapter 5: food, fibre, and forest products. In: Parry, M.L., Canziani, O.F., Palutikof, J.P., Linden, P.J.v.d., Hanson, C.E. (Eds.), Climate Change 2007: Impacts, Adaptation and Vulnerability. Contribution of Working Group II to the Fourth Assessment Report of the Intergovernmental Panel on Climate Change. Cambridge University Press, Cambridge, United Kingdom and New York, NY, USA, pp. 273-313.

Fischer, G., Shah, M., Tubiello, N., van Velhuizen, F.H., 2005. Socio-economic and climate change impacts on agriculture: an integrated assessment, 1990-2080. Philosophical Transactions: Biological Sciences 360 (1463), 2067-2083.

Funk, C., et al., 2008. Warming of the Indian Ocean threatens eastern and southern African food security but could be mitigated by agricultural development. Proceedings of the National Academy of Sciences 105 (32), 11081-11086.

Hertel, T.W. (Ed.), 1997. Global Trade Analysis: Models and Applications. Cambridge Univ Press, Cambridge, UK.

Hertel, T.W., 2011. The Global Supply and Demand for Land in 2050: A Perfect Storm? American Journal of Agricultural Economics, (forthcoming).

Hertel, T.W., Ivanic, M., Preckel, P.V., Cranfield, J.A.L., 2004. The earnings effects of multilateral trade liberalization: implications for poverty. The World Bank Economic Review 18 (2), 205-236.

Hertel, T.W., Keeney, R., Winters, L.A., 2007. Distributional effects of WTO agricultural reforms in rich and poor countries. Economic Policy 22 (50), 289-337.

Hertel, T.W., Rosch, S., 2010. Climate Change, Agriculture and Poverty. Applied Economic Perspectives and Policy 1 (3).

Hertel, T.W., Winters, L.A. (Eds.), 2006. Poverty and the WTO: Impacts of the Doha Development Agenda. Palgrave MacMillan, New York.
Jones, P.G., Thornton, P.K., 2003. The potential impacts of climate change on maize production in Africa and LatinAmerica in 2055. Global Environmental ChangeHuman and Policy Dimensions 13 (1), 51-59.

Keeney, R., Hertel, T.W., 2005. GTAP-AGR: A Framework for Assessing the Implications of Multilateral Changes in Agricultural Policies. Purdue University, West Lafayette, Indiana, U.S.A..

Lin, E., et al., 2005. Climate change impacts on crop yield and quality with $\mathrm{CO}_{2}$ fertilization in China. Philosophical Transactions: Biological Sciences 360 (1463), 2149-2154.

Lobell, D.B., et al., 2008. Prioritizing climate change adaptation needs for food security in 2030. Science 319 (5863), 607-610.

Lobell, D.B., Field, C.B., 2007. Global scale climate-crop yield relationships and the impacts of recent warming. Environmental Research Letters 2004000 (7 pp.).

Long, S.P., Ainsworth, E.A., Leakey, A.D.B., Nosberger, J., Ort, D.R., 2006. Food for thought: lower-than-expected crop yield stimulation with rising $\mathrm{CO}_{2}$ concentrations. Science 312 (5782), 1918-1921.

Matthews, R.B., Kropff, M.J., Bachelet, D., Van Laar, H.H., 1995. Modeling the Impact of Climate Change on Rice Production in Asia. CABI, Los Banos, Philippines.

Parry, M., Rosenzweig, C., Iglesias, A., Fischer, G., Livermore, M., 1999. Climate change and world food security: a new assessment. Global Environmental Change-Human and Policy Dimensions 9, S51-S67.

Parry, M.L., Canziani, O.F., Palutikof, J., Van der Linden, P., Hanson, C.E., 2007. Climate Change 2007: Impacts Adaptation and Vulnerability: Contribution of Working Group II to the Fourth Assessment Report of the Intergovernmental Panel on Climate Change. Cambridge Univ Press, Cambridge, UK, 976 pp.

Rosenzweig, C., Parry, M.L., 1994. Potential impact of climate-change on world foodsupply. Nature 367 (6459), 133-138.

Schlenker, W., Roberts, M.J., 2008. Estimating the Impact of Climate Change on Crop Yields: The Importance of Nonlinear Temperature Effects. NBER Working Paper 13799.

Schlenker, W., Roberts, M.J., 2009. Nonlinear temperature effects indicate severe damages to U.S. crop yields under climate change. Proceedings of the National Academy of Sciences 106 (37), 15594-15598.

Schmidhuber, J., Tubiello, F.N., 2007. Global food security under climate change. Proceedings of the National Academy of Sciences 104 (50), 19703.

Solomon, S., et al., 2007. IPCC, climate change 2007: the physical science basis. In: Contribution of Working Group I to the Fourth Assessment Report of the Intergovernmental Panel on Climate Change, Cambridge University Press, Cambridge, United Kingdom and New York, NY, USA, 996 pp.

Tebaldi, C., Lobell, D.B., 2008. Towards probabilistic projections of climate change impacts on global crop yields. Geophysical Research Letters 35, L08705 doi:10.1029/2008GL033423.

Valenzuela, E., Hertel, T.W., Keeney, R., Reimer, J.J., 2007. Assessing global computable general equilibrium model validity using agricultural price volatility. American Journal of Agricultural Economics 89 (2), 383-397.

Xiong, W., Lin, E., Ju, H., Xu, Y., 2007. Climate change and critical thresholds in China's food security. Climatic Change 81 (2), 205-221. 